July 2007

\title{
American Academy of Allergy, Asthma \& Immunology Work Group Report: Allergy diagnosis in clinical practice
}

\author{
Dana V. Wallace \\ Nova Southeastern University \\ Sami L. Bahna \\ Louisiana State University \\ Stan Goldstein \\ Allergy and Asthma Care of Long Island, NY \\ Robert G. Hamilton \\ Johns Hopkins University \\ John R. Cohn \\ Thomas Jefferson University \\ Follow this and additional works at: https://jdc.jefferson.edu/medfp \\ Part of the Medical Genetics Commons \\ Let us know how access to this document benefits you
}

\section{Recommended Citation}

Wallace, Dana V.; Bahna, Sami L.; Goldstein, Stan; Hamilton, Robert G.; and Cohn, John R., "American Academy of Allergy, Asthma \& Immunology Work Group Report: Allergy diagnosis in clinical practice" (2007). Department of Medicine Faculty Papers. Paper 26.

https://jdc.jefferson.edu/medfp/26

This Article is brought to you for free and open access by the Jefferson Digital Commons. The Jefferson Digital Commons is a service of Thomas Jefferson University's Center for Teaching and Learning (CTL). The Commons is a showcase for Jefferson books and journals, peer-reviewed scholarly publications, unique historical collections from the University archives, and teaching tools. The Jefferson Digital Commons allows researchers and interested readers anywhere in the world to learn about and keep up to date with Jefferson scholarship. This article has been accepted for inclusion in Department of Medicine Faculty Papers by an authorized administrator of the Jefferson Digital Commons. For more information, please contact: JeffersonDigitalCommons@jefferson.edu. 


\section{American Academy of Allergy, Asthma \& Immunology Work Group Report: Allergy diagnosis in clinical practice}

To the Editor:

At the request of the American Academy of Allergy, Asthma \& Immunology (AAAAI) Board, the Practice Diagnostics and Therapeutics Committee orchestrated the development of a paper entitled "AAAAI Work Group Report: Allergy Diagnosis in Clinical Practice' to communicate the optimal methods for the diagnosis of allergic disorders to the entire medical community. This letter represents the opinion of the work group, and it summarizes the key points of that report, which has been posted on the AAAAI Web site.

The diagnostic algorithm for allergic disorders starts with a chief complaint and comprehensive history, which is often the most important and definitive diagnostic tool available to the clinician. It is important to determine the onset, frequency, severity, pattern, triggers, and success or failure of prior treatment for each allergic symptom. The presence of related comorbid allergic problems must also be determined in the review of systems. It is important to assess the effect of the allergic symptoms on the patient's quality of life, eg, days missed from work or school and emergency room visits. The allergist will review the family history of allergic and medical problems, an environmental survey, occupational exposure, and social history. Physical examination should be conducted with emphasis on the organs affected by the allergic complaints. Diagnostic procedures may be required, eg, spirometry for asthma or determination of immediate-type hypersensitivity to identify allergenic triggers for of the patient's symptoms. Additional office-based diagnostic procedures such as rhinolaryngoscopy, tympanometry, oral provocation testing for foods or medications, and patch testing for delayed-type hypersensitivity may be used for certain evaluations.

Skin testing, prick/puncture and/or intracutaneous, is used to help confirm the clinical history in the evaluation of suspected inhalant, food, insect, and drug allergy and remains the preferred technique for most allergists. These in vivo procedures have demonstrated reliability, speed, cost effectiveness, and ease of performance. They are appropriate for any age patient and allow direct observation of a biologic response in the patient. Specific allergen tests along with histamine (positive control) and human albumin saline (negative control) are applied to the back and/or arm of the patient. The wheal and flare responses are recorded in $\mathrm{mm}$ (diameter or area) at 15-20 minutes following application for prick/puncture and 10-15 minutes for intracutaneous tests. Although a 0 to 14 scoring scale is often used, it should not replace the measurement of induration and erythema. Although a $3 \mathrm{~mm}$ increase in wheal size over the negative control is generally considered a positive prick/puncture test result, there is much less agreement on what constitutes a significantly positive intradermal skin test result. In general, reactivity by prick/puncture testing is the most specific, whereas intradermal testing is more sensitive. The diagnostic accuracy of intracutaneous tests is greater than prick/puncture when testing with insect venom or certain drugs, but appropriate interpretation in the evaluation of inhalant allergy remains controversial despite widespread use. The diagnostic validity of the prick/puncture tests has been confirmed by natural exposure and organ allergy challenge. The reliability of both types of skin tests depends upon the skill of the

This is a preprint of a letter that was published in Journal of Allergy and Clinical Immunology 120(4):927-969. The published version is available at doi:10.1016/j.jaci.2007.05.049 
tester and the potency and stability of the test reagents. Variability of skin reactivity in an individual patient may relate to such factors as age (less reactivity in infants and the elderly), skin color, time of day, timing in relation to pollen season (eg, increased reactivity following pollen season), and placement on the body (eg, the back is more reactive than the forearm). Skin testing will, in general, start with prick/ puncture testing, the safer of the skin testing techniques. It may be followed by intracutaneous tests for inhalant allergens only when prick/puncture skin test results are negative and increased sensitivity is the main objective, eg, due to a convincing history of exposure and symptoms, lower skin prick test reactivity, or low potency allergenic extracts. In a recent survey of US allergists, $85.2 \%$ performed intradermal skin tests for inhalant allergens. Although less allergen is introduced for the prick/puncture tests, life-threatening systemic reactions are rarely caused by either method of testing. However, the clinician must have experience in treating adverse reactions and appropriate resources available for treating anaphylaxis.

There are several important precautions to take when planning allergy skin testing. Antihistamines should usually be discontinued for 3-10 days depending upon the agent. Tricyclic antidepressants and some tranquilizers may need to be discontinued for up to a few weeks. As patients taking a b-blocker may be more difficult to treat in the event of a systemic reaction, current allergy diagnostic and immunotherapy practice parameters recommend that a cautious attitude toward these agents should be maintained, avoiding their concurrent use during allergy testing and immunotherapy when possible. ${ }_{7}^{2,6}$ Although the use of an angiotensin-converting enzyme inhibitor and monoamine oxidase inhibitors in patients undergoing skin testing has been questioned based upon potentially increased risk of more severe anaphylaxis in other situations, no increased risks have been demonstrated for allergydirected diagnosis or treatment in patients being treated with these agents.

Newer in vitro specific IgE assays such as the ImmunoCAP (Pharmacia Diagnostics, Uppsala, Sweden) and Immulite (Diagnostics Product Corporation, Los Angeles, Calif) replace the older RAST. With these assays, the allergist has an alternative method for screening allergy testing. The test can detect sensitization as evidenced by the presence of $\operatorname{IgE}$ antibody specific for a given allergen. However, as in skin testing, an important role for the clinician is interpreting what level of IgE antibody is clinically significant. When interpreting the significance of the quantitative level, the total IgE must be taken into consideration, as, for example, an extremely high total level can be associated with many "positive" results that are not clinically relevant. Allergen-specific IgE antibody measurements from different laboratories may not be equivalent. Ideally the commercial laboratory is Clinical Laboratory Improvement Act of 1988 certified, uses an allergosorbent that has been Food and Drug Administration-cleared, is able to provide an external proficiency survey demonstrating reliability and reproducibility, and uses an $\mathrm{IgE}$ antibody assay that reports results in quantitative $\mathrm{kUA} / \mathrm{L}$ units. Although a detailed review of the laboratory by the clinician prior to ordering in vitro testing can be important in selecting the preferred laboratory and method for specific IgE testing, this is not always possible because laboratory selection may be dictated by the third-party payor.

This is a preprint of a letter that was published in Journal of Allergy and Clinical Immunology 120(4):927-969. The published version is available at doi:10.1016/j.jaci.2007.05.049 
Advantages of in vitro testing include elimination of any systemic reaction risk (eg, severe food, drug, or insect sting allergy), continuation of the patient's current medications, and use in patients with severe eczema or dermographism. It also provides an option for nonallergists to use a multiple-allergen screening test, eg, testing up to 15 aeroallergens with 1 test, which has been shown to have a high negative predictive value compared with prick/ puncture testing. ${ }^{2}$ Disadvantages include a delay in obtaining results, the lack of visible "proof" for the patient, and the possibility of false-negative results not confirmed by a second technique as occurs when prick/puncture testing is followed by selected intracutaneous tests. Assessment of food specific IgE levels may be used to eliminate the need for oral food challenges based on certain cut-off levels and predictive values. However, for insect venom and drugs, it is advised to use a combination of in vitro specific $\operatorname{IgE}$ and in vivo percutaneous and intradermal skin testing.

The number of specific IgE tests performed in individual patients is guided by the patient's age (eg, more foods and less aeroallergens in the young child), seasonal versus nonseasonal symptoms, botanical cross-sensitivity, occupation, anaphylaxis to foods, drugs, or venom, and frequent travel to other floristic zones. The experienced clinician recognizes that at times, negative results are as helpful as positive results in patient management. In interpreting specific IgE tests, a positive test result indicates sensitization and does not necessarily mean that symptoms are due to an IgE-mediated allergy.

Organ challenge, with allergen applied topically, by inhalation, or ingestion, to the skin or the mucosa of the conjunctivae, nares, bronchi, or gastrointestinal tract is often considered the gold standard when there is poor correlation of specific IgE measures with clinical symptoms. Experience and appropriate precautions with these methods are required for proper testing and interpretation. Although organ challenges are often considered a research tool, a commonly used in-office procedure is titrated food challenge testing, preferably in a doubleblind or a single-blind manner.

It is ultimately up to the experienced and skilled clinician to combine the elements of medical history, physical findings, and diagnostic allergy testing to reach a correct diagnosis and to formulate an appropriate treatment plan.

Dana V. Wallace, MD ${ }^{\mathrm{a}}$ Sami L. Bahna, MD, DrPH ${ }^{\mathrm{b}}$ Stan Goldstein, MD ${ }^{\mathrm{c}}$ Robert G. Hamilton, $\mathrm{PhD}^{\mathrm{d}}$ John R. Cohn, MD

From:

${ }^{\mathrm{a}}$ Nova Southeastern University, Davie, FL

the Departments of Medicine and Pediatrics, Louisiana State University Health Sciences Center, Shreveport, LA

${ }^{\mathrm{c}}$ Allergy and Asthma Care of Long Island, Rockville Centre, NY

d Johns Hopkins University School of Medicine, Baltimore, MD

This is a preprint of a letter that was published in Journal of Allergy and Clinical Immunology 120(4):927-969. The published version is available at doi:10.1016/j.jaci.2007.05.049 
'Thomas Jefferson University, Philadelphia, PA.

E-mail: john.cohn@mail.tju.edu.

Disclosure of potential conflict of interest: S. Goldstein has served on the speakers' bureau for Schering-Plough, GlaxoSmithKline, AstraZeneca, Sanofi Aventis, and Genetech Novartis. The rest of the authors have declared that they have no conflict of interest.

\section{REFERENCES}

1. Cohn JR, Bahna SL, Wallace DV, Goldstein S, Hamilton RG. AAAAI Work Group Report: Allergy diagnosis in clinical practice. Available at: http://www.aaaai.org/media/resources/academy_statements/practice_papers/ allergy_diagnosis.pdf . Accessed November 2006.

2. Bernstein IL, Li JT, Bernstein DI, Hamilton R, Spector S, Tan R, et al. Allergy diagnostic testing: an updated practice parameter. Ann Allergy Asthma Immunol 2007. In press.

3. Oppenheimer J, Nelson HS. Skin testing: a survey of allergists. Ann Allergy Asthma Immunol 2006;96:19-23.

4. Oppenheimer JJ, Nelson HS: Seasonal variation in immediate skin test reactions. Ann Allergy 1993;71:227-9.

5. Joint Task Force on Practice Parameters; American Academy of Allergy, Asthma and Immunology; American College of Allergy, Asthma and Immunology; Joint Council of Allergy, Asthma and Immunology. The diagnosis and management of anaphylaxis: an updated practice parameter. J Allergy Clin Immunol 2005;115:S483-523.

6. Lieberman P, Kemp SF, Oppenheimer J, Lang DM, Bernstein IL, Nicklas RA. Reply [letter]. J Allergy Clin Immunol 2005;116:933-5.

7. Kemp SF, Lieberman P. Inhibitors of angiotensin II: potential hazards for patients at risk for anaphylaxis? Ann Allergy Asthma Immunol 1997;78: 527-9.

8. Sampson HA, Ho DG. Relationship between food-specific IgE concentrations and the risk of positive food challenges in children and adolescents. J Allergy Clin Immunol 1997;100:444-51.

9. Bahna SL. Food challenge procedures in research and in clinical practice. Pediatr Allergy Immunol 1995;6(Suppl 8):49-53. 